\title{
Photobiomodulation of gingival lesions resulting from autoimmune diseases: systematic review and meta-analysis
}

\author{
Milena Moraes de Carvalho ${ }^{1}$ - Marco Antonio Rimachi Hidalgo ${ }^{2} \cdot$ Raquel Mantuaneli Scarel-Caminaga $^{2}$. \\ Noé Vital Ribeiro Junior ${ }^{1} \cdot$ Felipe Fornias Sperandio ${ }^{3,4}$. Suzane Cristina Pigossi ${ }^{1} \cdot$ Marina Lara de Carli ${ }^{1}$
}

Received: 30 September 2021 / Accepted: 29 December 2021 / Published online: 13 January 2022

(C) The Author(s), under exclusive licence to Springer-Verlag GmbH Germany, part of Springer Nature 2022

\begin{abstract}
Objectives To evaluate the effects of photobiomodulation (PBM) in gingival lesions resulting from autoimmune diseases; to compare PBM and topical corticosteroid (CS) treatment; and to assess PBM outcome over time of follow-up.

Materials and methods A comprehensive electronic search was performed in four electronic databases. Treatment effects were measured through visual analog scale of pain (VAS) and clinical evolution of lesion (Thongprasom scale for oral lichen planus (OLP)). Meta-analysis was performed to compare PBM with topical corticosteroid treatment and to evaluate PBM effect over time of follow-up.

Results Seventeen studies were included in this review, of which six were used for the meta-analysis. Meta-analysis results showed no significant differences between PBM and topical CS in pain reduction at baseline $(\mathrm{MD}=0.20,95 \% \mathrm{CI}=-0.92$, $1.32, p=0.72)$ and 60-day follow-up ( $\mathrm{MD}=0.63,95 \% \mathrm{CI}=-3.93,5.19, p=0.79)$; however, VAS showed significant pain reduction when compared before and after PBM at 30-day $(\mathrm{MD}=-3.52,95 \% \mathrm{CI}=-5.40,-1.64, p=0.0002)$ and 60 -day $(\mathrm{MD}=-5.04,95 \% \mathrm{CI}=-5.86,-4.22, p<0.00001)$ follow-up. Thongprasom clinical scale for OLP also showed significant improvement at 30-day follow-up $(\mathrm{MD}=-2.50,95 \% \mathrm{CI}=-2.92,-2.08, p<0.00001)$ after PBM.

Conclusion PBM led to significant reduction of pain and clinical scores of the lesions, not having shown significant differences when compared to topical CS.

Clinical relevance PBM has been used in the treatment of autoimmune gingival lesions, but so far there is little strong evidence to support its use.
\end{abstract}

Keywords Benign mucous membrane pemphigoid $\cdot$ Oral lichen planus $\cdot$ Pemphigus vulgaris $\cdot$ Photobiomodulation therapy

\section{Introduction}

Marina Lara de Carli

marina.carli@unifal-mg.edu.br

1 School of Dentistry, Federal University of Alfenas, Rua Gabriel Monteiro da Silva, 700 - Centro, Alfenas, MG 37130-001, Brazil

2 Department of Morphology, Genetics, Orthodontics and Pediatric Dentistry, School of Dentistry at Araraquara, FOAr/UNESP), UNESP - São Paulo State University, Araraquara, SP, Brazil

3 Department of Pathology and Parasitology, Institute of Biomedical Sciences, Federal University of Alfenas, Alfenas, MG, Brazil

4 Faculty of Dentistry, University of British Columbia, Vancouver, BC, Canada
Autoimmune diseases relate to an exaggerated immune response that leads to damage and dysfunction of single or multiple organs and tissues [1]. These diseases cause the destruction of tissues and happen on a background of genetic predisposition and environmental factors that trigger immunological pathways. Furthermore, the failure to distinguish self from non-self tissues or cells is known as violation of tolerance and is the basis for these illnesses [2]. A wide range of autoimmune diseases can affect the oral cavity, although the most common are oral lichen planus (OLP), mucous membrane pemphigoid (MMP), pemphigus vulgaris (PV), and epidermolysis bullosa acquisita (EBA) [3]. In addition, oral lesions may be the first and occasionally the only clinical manifestation of several immunological disorders that affect the skin and mucosal surface [4]. 
OLP is a chronic inflammatory disease of autoimmune origin, mediated by $\mathrm{T}$ lymphocytes, which affects stratified squamous epithelial tissue; however, etiology and pathogenesis are not completely known [5]. Oral manifestations typically include hyperkeratotic striation/reticulation and/ or a variable degree of erythema, blistering, erosion, and ulceration [6] and the most commonly affected sites in the oral cavity are the buccal mucosa, tongue, and gingiva [7, 8]. In turn, MMP is a group of chronic, inflammatory, immunemediated sub-epithelial bullous diseases, which manifest a heterogeneous pattern of oral, ocular, cutaneous, genital, nasopharyngeal, esophageal, and laryngeal lesions [9]. The oral cavity and, in particular, the gingival tissue are the most commonly affected sites, accounting for $83-100 \%$ of all MMP patients [10]. Furthermore, patients diagnosed with this comorbidity have higher levels of gingival inflammation and periodontal parameters than healthy control patients, and comparable data were also seen in gingival OLP [11, 12].

Another autoimmune disease with an important oral manifestation is $\mathrm{PV}$, comprising a group of rare autoimmune bullous diseases that affect the skin and mucous membranes [13]. Oral lesions usually precede skin lesions or are the only manifestation of the disease, affecting areas such as the lips, gingiva, oral mucosa, and palate [14]. Oral manifestations of PV can be very painful, disrupting oral intake and, consequently, affecting patients' quality of life on a negative manner [15].

Despite their heterogeneous nature, all the disorders mentioned above share two characteristics: an immune-mediated pathogenesis and possibly a common clinical picture represented by oral lesions, with special attention to those in the gingival form [16]. In general, the gingival lesions caused by autoimmune dermatologic disorders are described with diffuse erythematous lesions, blisters, erosions, or ulcerations, mainly located on the attached gingiva and on the palate and are called desquamative gingivitis (DG), a term proposed by Prinz in 1932 [3, 17]. Thus, it is known that DG is a clinical finding with several potential etiologies, and although there are other differential diagnoses, OLP, MMP, and PV are the most common [18]. According to different case series, MMP is responsible for 35 to $48 \%$ of cases of DG. OLP and PV account for 24 to $45 \%$ and 3 to $15 \%$ of cases, respectively [19-25].

Currently, there are specific treatments that focus on the general manifestations of the disease that are related to its pathogenesis. Topical corticosteroids (CS) have been indicated through different formulations and prescribed with different dosages, in topical or systemic forms, in addition to other drugs such as immunosuppressants and broadspectrum antibiotics $[18,26]$. However, although the abovementioned diseases share similarities, even individuals with identical clinical presentations may respond differently to a given therapy. This means that instead of applying a "standard treatment" for all patients, there is a need to subdivide individuals into more homogeneous groups in order to utilize more specific and individualized treatments that would be rather more effective [27]. In addition to the variable patients' outcomes, the use of systemic steroids presents an increased risk of adverse side effects. Consequently, alternative treatment modalities have emerged. Among them, photobiomodulation (PBM), also called low-level laser therapy (LLLT), or laser therapy, stands out [14, 28, 29]. Different types of laser (ultraviolet, helium-neon, and diode) with distinct doses, output power, and time of irradiation are applied to the injury site and the irradiation is repeated for several sessions [30]. They can be used due to their proposed antiinflammatory effects, pain relief, and accelerated regeneration of damaged tissues, without demonstrating the adverse effects associated with drug intake treatment [28, 29]. Therefore, the purpose of this systematic review is to access the effects of PBM when used in gingival lesions resulting from autoimmune diseases, including OLP, MMP, and PV.

\section{Materials and methods}

\section{Protocol registration and focused question}

This systematic review was conducted in accordance with the Preferred Reporting Items for Systematic Reviews and Meta-Analyses (PRISMA) and a protocol was registered in the International Prospective Register of Systematic Reviews (PROSPERO-CRD42020200843). We established our research question according to the Participants, Interventions, Control, and Outcomes (PICO) principle. The focused question of interest was "Is PBM effective to treat autoimmune gingival lesions?".

Population Patients with gingival lesions due to autoimmune diseases, including OLP, oral MMP, and oral $\mathrm{PV}$

Intervention Gingival autoimmune lesions treated with PBM

Comparison Autoimmune gingival lesions treated with conventional drug therapy or other treatment modality (when comparative groups exist)

Outcome To verify the efficacy of PBM in autoimmune gingival lesions.

\section{Eligibility criteria}

The eligibility criteria were as follows: all case reports, case series, longitudinal studies, and randomized clinical trials, in which the patients presented gingival lesions due to autoimmune diseases, including OLP, oral MMP, and oral PV, 
and that were treated with PBM. Children, pregnant women, and patients with only cutaneous, ocular, or genital lesions were not included in this review. Additionally, in vitro and in vivo studies, review papers, book chapters, conference proceedings, protocol articles, studies with insufficient data to perform qualitative analysis, studies that did not fulfill the diagnostic criteria, and published studies in a language other than English were excluded from the study.

\section{Literature search}

Electronic searches were carried out in four databases for publications until July 2020: National Library of Medicine, Washington, D.C. (MEDLINE-PubMed); Embase®; Scopus, and ISI Web of Science. Keywords were selected according to Medical Subject Headings (MeSH-National Center for Biotechnology Information (NCBI)) and considering the PICO criteria; the keywords were combined as follows: "lichen planus, oral, or oral lichen planus" and "photobiomodulation therapy, or photobiomodulation therapies or low-level light therapy or low-level light therapies or light therapies, low-level or light therapy, low-level or therapies, low-level light or therapy, low-level light or therapies, photobiomodulation or therapy, photobiomodulation or LLLT or laser therapy, low-level or laser therapies, low-level or laser therapy, low level or low-level laser therapies or laser irradiation, low-power or irradiation, low-power laser or laser irradiation, low power or low-power laser therapy or low power laser therapy or laser therapy, low-power or laser therapies, low-power or laser therapy, low power or low-power laser therapies or low-level laser therapy or low level laser therapy or low-power laser irradiation or low power laser irradiation or laser biostimulation or biostimulation, laser or laser phototherapy or phototherapy, laser." The same combinations were made between treatment and oral MMP ("mouth" or "oral" and "pemphigoid, benign mucous membrane" or "benign mucosal pemphigoid" or "benign mucosal pemphigoids" or "mucosal pemphigoid, benign" or "mucosal pemphigoids, benign" or "pemphigoid, benign mucosal" or "pemphigoids, benign mucosal" or "pemphigoid, cicatricial" or "cicatricial pemphigoid" or "benign mucous membrane pemphigoid" or "mucous membrane pemphigoid, benign" or "ocular cicatricial pemphigoid" or "cicatricial pemphigoids, ocular" or "ocular cicatricial pemphigoids" or "pemphigoids, ocular cicatricial" or "pemphigoid, ocular cicatricial" or "cicatricial pemphigoid, ocular") and between treatment and oral PV ("mouth or oral" and "pemphigus or pemphigus vulgaris").

\section{Screening and selection}

The studies were selected by two independent researchers (MMC and MLC). Titles and abstracts of retrieved articles were screened for eligibility, considering the inclusion/ exclusion criteria described above, and irrelevant studies were excluded. Following this, full texts of the studies that met the eligibility criteria were selected and were accessed by both authors for inclusion. Disagreements between the investigators were resolved by consensus or were referred to a third review author (SCP) for the final decision. Studies that met the selection criteria were processed for data extraction. Figure 1 describes the screening process according to PRISMA guidelines.

\section{Data extraction}

Two reviewers (MMC and MLC) performed the data extraction independently. The general characteristics of the studies were collected and divided into two tables: Table 1 (articles without a control group) and Table 2 (articles with a control group). The qualitative data from these studies was tabulated according to the study type, number, mean age, and gender of the subjects and diagnosis, as well as the method used, follow-up period, evaluation methods, and main outcomes (Tables 1 and 2).

Furthermore, the laser parameters of the included studies were also collected. This information can be seen in Table 3 . At this stage, we also accessed the quantitative data from studies for later realization to the meta-analysis.

\section{Quality assessment}

Two authors (SCP and MMC) assessed the quality of the included studies separately. Any disagreement was discussed with a third reviewer (MLC). The methodological quality of case reports and case series was evaluated using the framework for appraisal suggested by Murad et al. [31] based on the domains of selection, ascertainment, causality, and reporting. Randomized clinical studies were evaluated using the Cochrane collaboration tool [32], and for non-randomized studies, the RoBANS (Risk of Bias Assessment Tool for Nonrandomized Studies) scale was used [33]. The judgement of case reports and case series was made based on the issues considered most critical. Six points were awarded for studies of the highest quality. A total score equal or below 2 was determined as "low quality," a score of 3 or 4 was determined as "moderate quality," and a score equal or above 5 was determined as "high quality." In turn, clinical studies were assessed for the risk of bias within six domains, which were judged to be uncertain, low, or high risk.

\section{Measures of treatment effect}

Treatment effects were measured through visual analog scale of pain (VAS) and clinical evolution of lesion (Thongprasom scale) [34]. 
Fig. 1 Criteria for the selection of articles. Flowchart of methodology according to PRISMA guidelines
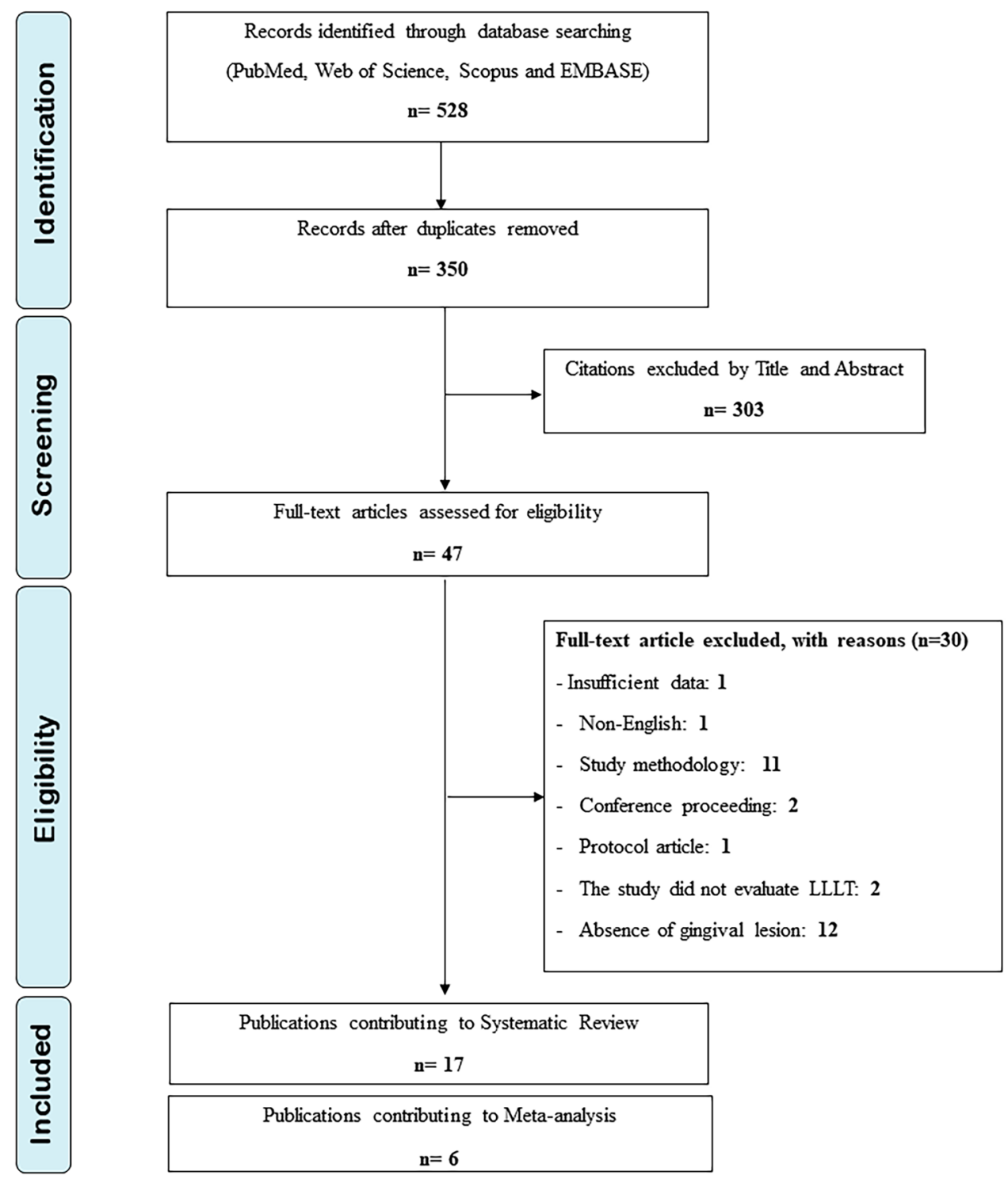

\section{Data synthesis}

In the meta-analysis, the studies were separated into laser vs. control group and laser outcome (PBM outcome over followup periods). For the studies with no control, a comparison of the laser effect over time of follow-up was made. The number of individuals per group, the age of each group (mean and standard deviation), the numerical values of mean, and standard deviation of evaluation criteria were assessed. Studies with no control were grouped considering VAS scores and Thongprasom clinical scores. The effect size was estimated and reported as the mean difference (MD). Statistical software (Review Manager [RevMan], version 5.1. Copenhagen: The Nordic Cochrane Centre, The Cochrane Collaboration, 2011) was used to pool the data and to produce the forest plots. Additionally, narrative analysis to explore the relationship between studies was performed.

\section{Results}

\section{Study selection}

A total of 528 potentially relevant studies were initially identified. By removing the duplicate articles, 350 remained. After evaluation of titles and abstracts, 214 were identified as in vivo or in vitro studies, reviews, articles that are not written in English, book chapters, conference papers, and letters to the editor, and were thus deleted. The remaining 136 articles underwent a new evaluation and 89 studies were removed because they did not meet the inclusion criteria. Therefore, a total of 47 articles were selected for thorough full-text reading. After full-text screening, 17 of the 47 studies were included in the current review [9, 14, 35-47] and 30 were excluded. The reasons for excluding these articles can be seen in the study identification 


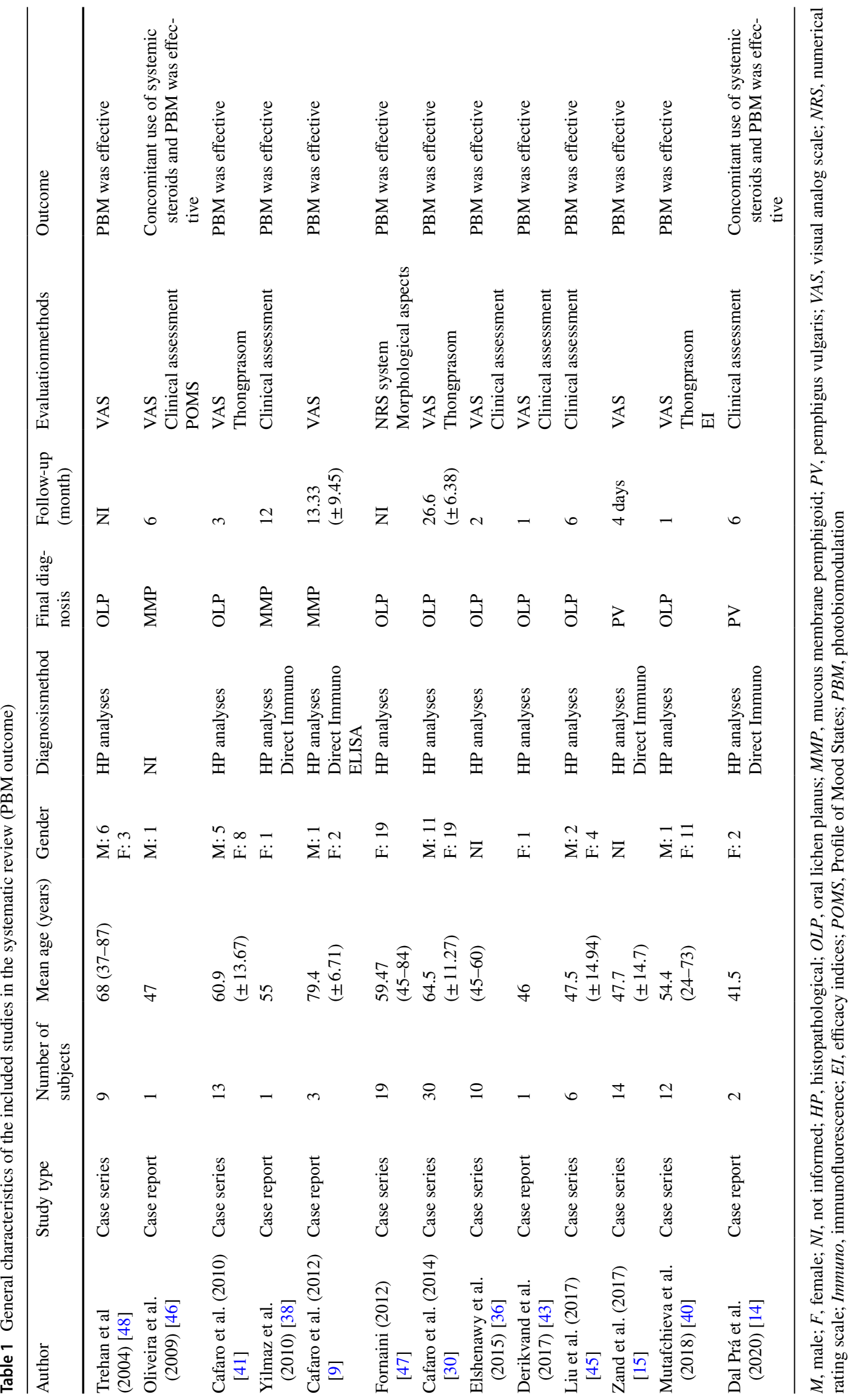




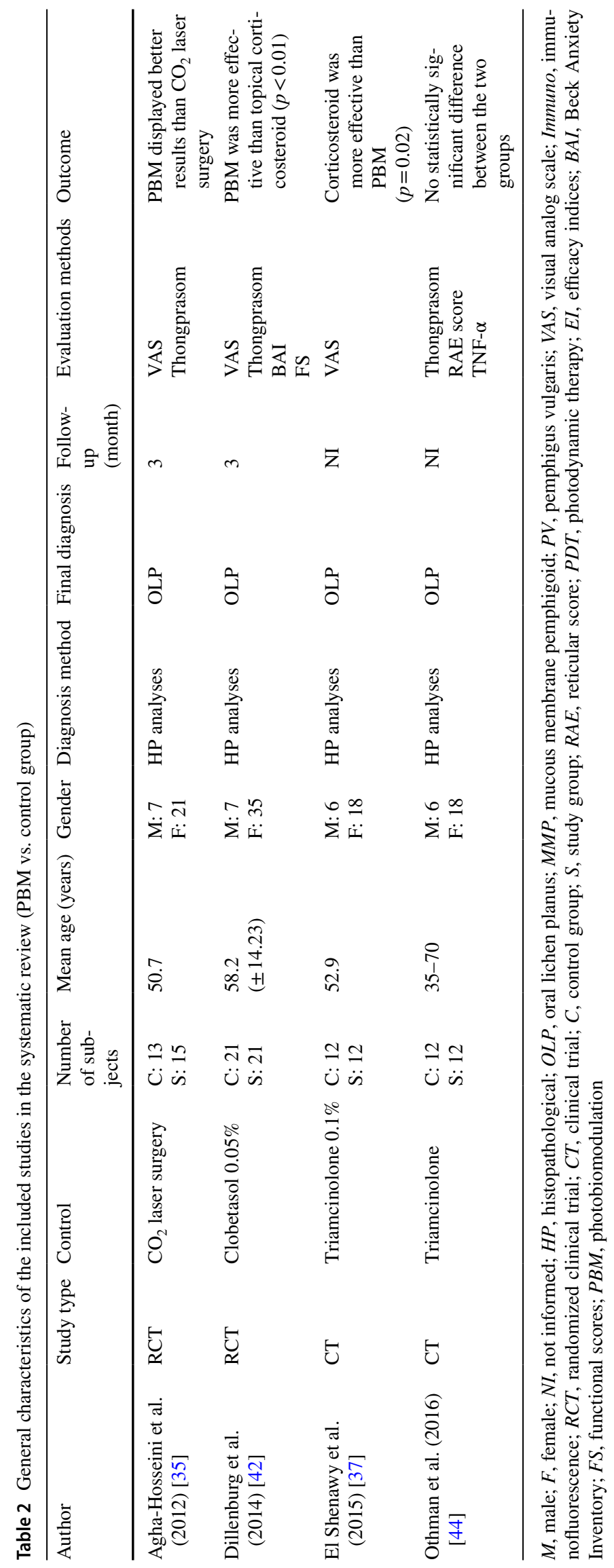




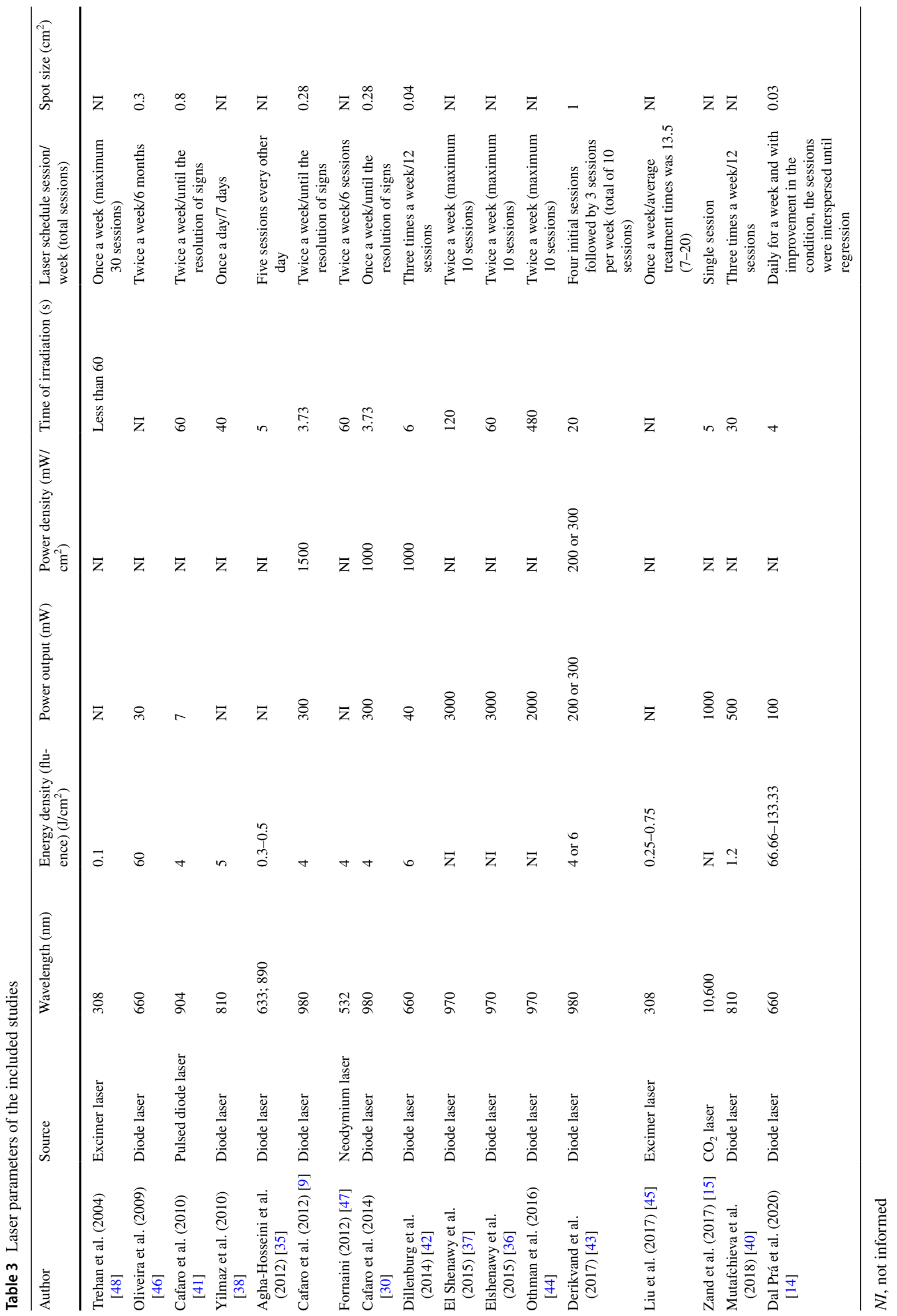


flowchart according to PRISMA (Fig. 1). Only 6 articles $[9,30,36,37,41,42]$ presented adequate quantitative data, making it possible to carry out the meta-analysis.

\section{Qualitative evaluation}

Seventeen published articles were included in the qualitative evaluation [9, 14, 30, 35-48], for a total of 239 patients with oral lesions resulting from autoimmune diseases. Type of study, number, mean age and sex of the subjects, diagnosis, as well as the diagnostic method used, follow-up period, evaluation methods, and main outcomes can be seen in Tables 1 and 2.

Most of the studies included in this systematic review were case series ( 8 papers, $47 \%$ ), followed by case reports (5 papers, 29.4\%), randomized controlled trials (RCTs), and non-RCTs ( 2 papers, $11.8 \%$ each). The number of subjects ranged between 1 and 42 individuals in the included studies. Two studies did not report gender of the subjects, while in the remaining fifteen studies majority of the subjects were females $(75.35 \%)$.

Among the 239 cases included herein, 141 (11 articles) confirmed the presence of gingival lesions and 98 ( 6 articles) did not indicate the specific location of the oral lesions. Of the 141 informed cases, just 1 case (1 study) showed isolated desquamative gingivitis. The remaining 140 cases presented gingival involvement and other concomitant intraoral sites, in which the buccal mucosa and the tongue were affected in 136 of them $(97.14 \%)$.

OLP was the most prevalent diagnosis, representing $91.21 \%$ of the cases $(n=218)$; PV was found in sixteen cases (6.7\%) and MMP in only five cases (2.09\%). Histopathological analysis was the sole diagnostic method in 218 cases (91.6\%); in other cases, a combination of methods was used for reaching the diagnosis, namely combining histology with direct immunofluorescence in 17 cases (7.14\%), or even associating enzyme-linked immunosorbent assay (ELISA) to these two techniques ( 3 cases, 1.26\%). Only 1 case ( 1 study) did not reveal the diagnostic method used.

All included studies reported the effect of PBM on pain alleviation and clinical enhancement of the oral lesions. To assess pain levels before and after PBM, the most used method was the VAS, used in twelve articles (70.6\%). Four articles (23.5\%) did not perform this measurement and only one used another method of pain assessment, the NRS system. Regarding clinical evaluation of the lesions, the Thongprasom scale was used in six studies $(35.3 \%)$; other seven articles performed only clinical assessments and observed the morphological aspects of the lesions with no classification. In addition to VAS and Thongprasom sign scoring, one study verified treatment efficacy index (EI), one assessed levels of anxiety and functional scores (FS), and another article evaluated reticular score (RAE) and the serum pro-inflammatory mediators. Furthermore, an evaluation of the Profile of Mood States (POMS) was also found in one article. Follow-up period was reported in thirteen studies (76.5\%), with an average of 6.4 months, ranging from 4 days to 26.6 months.

Thirteen included articles (76.5\%) did not present comparative groups and only four (23.5\%) resorted control groups. Three studies compared the efficacy of PBM with CS and one compared the efficacy of PBM to $\mathrm{CO}_{2}$ laser surgery (Table 2), being two articles $(59.32 \%)$ [35, 42] showing PBM better than the control group $\left(\mathrm{CO}_{2}\right.$ laser surgery [35] and clobetasol $0.05 \%$ [42]).

With regard to studies with no comparative groups (13 papers), PBM was effective over time of follow-up on all of them $[9,14,15,30,36,38,40,41,43,45-48]$. In 11 studies $(84.6 \%)$, the laser was applied singly and in 2 studies $(15.4 \%)$, it was used concurrently with steroid therapy (Table 1). Five articles reported the effect of the laser directly on the gingival tissues [14, 30, 38, 41, 48]. Three studies $[14,30,38]$ showed that all gingival cases were successfully treated with PBM, while two studies [41, 48] reported unsatisfactory response to the laser for some patients. The remaining twelve papers showed general results, without individualizing or differentiating the outcomes according to the lesion site.

\section{Laser parameters of included studies}

The laser parameters used in the included studies showed a great variation (Table 3). The laser source most used was diode laser, seen in twelve papers (178 cases). The second source found was excimer laser (used with low level in 2 studies, 15 cases), followed by neodymium laser, $\mathrm{CO}_{2}$ laser (low level), and pulsed diode laser (1 article, each). In all studies, laser was used with wavelengths ranging from 308 to $10,600 \mathrm{~nm}$ and power output ranging from 0.007 to $3 \mathrm{~W}$. Most of the articles did not report power density values (14-82.3\%). Twelve papers reported laser fluence/energy density that ranged from $0.1 \mathrm{up}$ to $133.3 \mathrm{~J} / \mathrm{cm}^{2}$.

Concerning exposure time, a variation between the studies from $3.73 \mathrm{~s}$ to $8 \mathrm{~min}$ was observed. Only six studies reported the spot size of the laser, which ranged between 0.03 and $0.8 \mathrm{~cm}^{2}$. The number of reported laser sessions ranged from one single session to 48 sessions.

\section{Quality assessment}

Regarding the case reports and case series, a total of seven studies were considered with high quality and six with moderate quality (Table 4). The quality assessment of non-randomized clinical studies can be seen in Table 5. For details about the quality assessment of randomized clinical studies, see Fig. 2. 


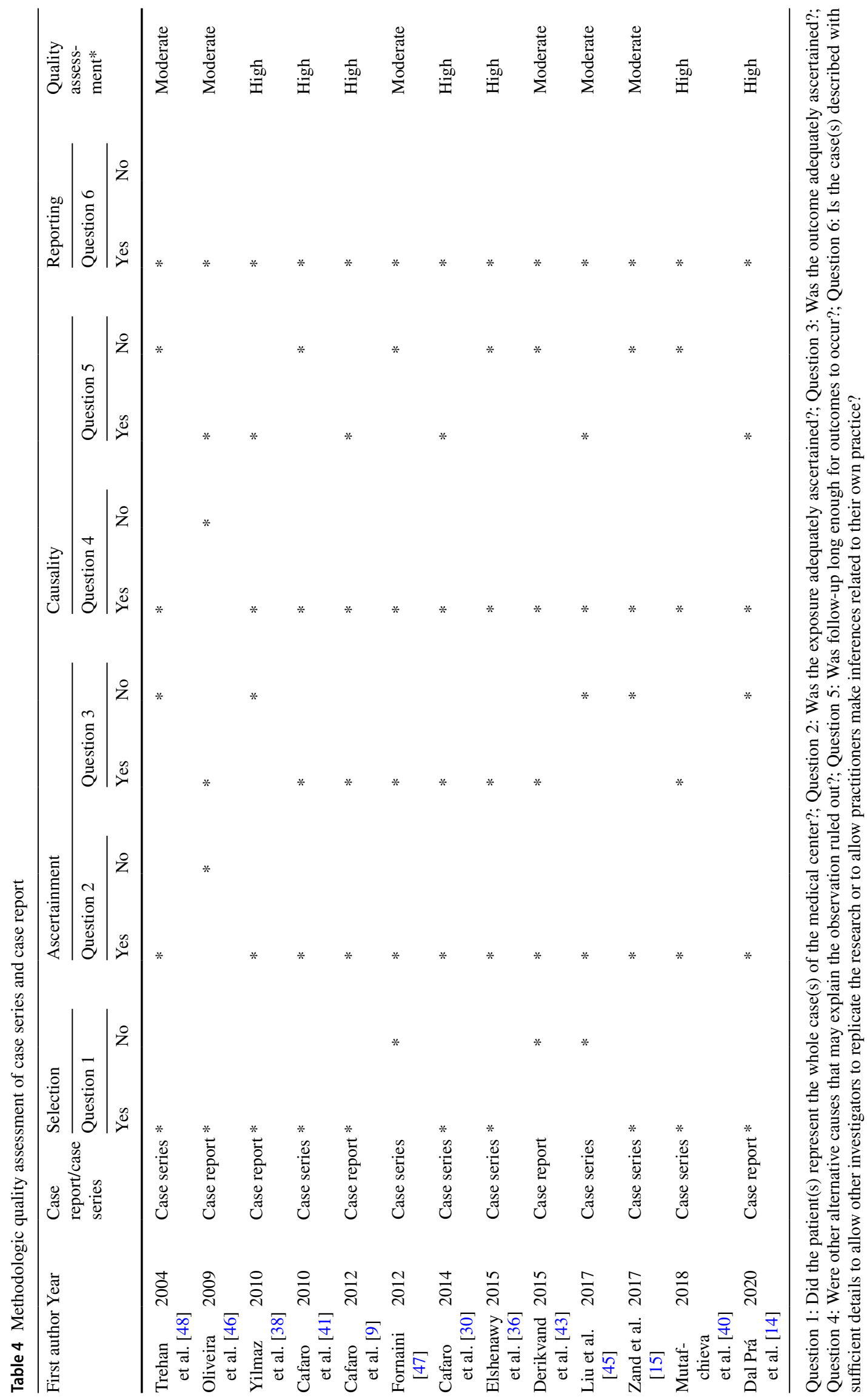


Table 5 Methodologic quality assessment of non-randomized clinical studies

\begin{tabular}{lllllllll}
\hline First author & Year & \multicolumn{2}{l}{ Domain } & & & \\
\cline { 3 - 8 } & & $\mathbf{1}$ & $\mathbf{2}$ & $\mathbf{3}$ & $\mathbf{4}$ & $\mathbf{5}$ & $\mathbf{6}$ \\
\hline El Shenawy et al. [37] & 2015 & Low & Low & Unclear & High & Low & Low \\
Othman et al. [44] & 2016 & High & High & High & High & Low & Unclear \\
\hline
\end{tabular}

Domain 1: Selection bias caused by inadequate selection of participants; Domain 2: Selection bias caused by inadequate confirmation and consideration of confounding variable; Domain 3: Performance bias caused by inadequate measurement of intervention (exposure); Domain 4: Detection bias caused by inadequate blinding of outcome assessment; Domain 5: Attrition bias caused by inadequate handling of incomplete outcome data; Domain 6: Reporting bias caused by selective outcome reporting

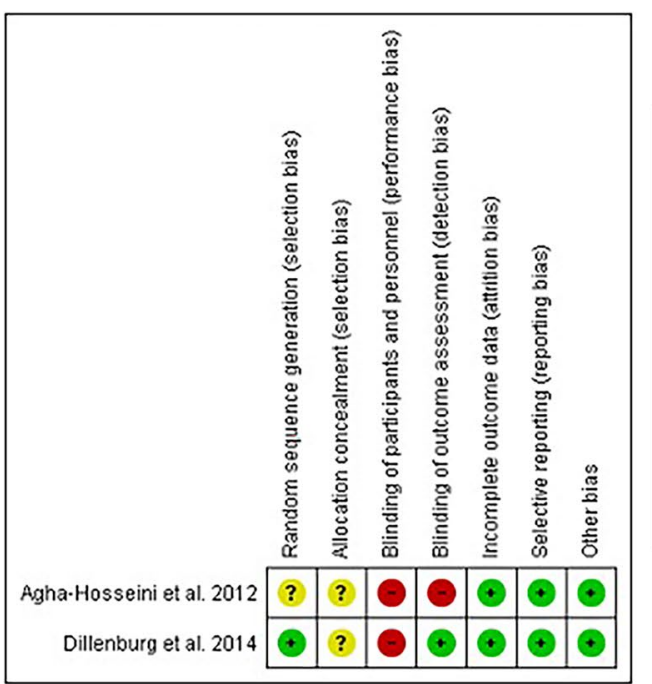

Fig. 2 Methodological quality assessment of randomized clinical trials. a Risk of bias summary: review authors' judgements about each risk of bias item for each included study. b Risk of bias graph: review

\section{Quantitative evaluation (meta-analysis)}

In order to assess VAS scores between PBM and control groups (CS), we extracted the data from two studies allowing for baseline and 60-day follow-up analyses. No statistically significant differences between the PBM and CS groups for pain at baseline $(\mathrm{MD}=0.20,95 \% \mathrm{CI}=-0.92$, $1.32, p=0.72$ ) (Fig. 3a) and at 60-day follow-up ( $\mathrm{MD}=0.63$, $95 \% \mathrm{CI}=-3.93,5.19, p=0.79$ ) (Fig. 3b) were found.

The effect of PBM over time of follow-up in studies with no control group was assessed through VAS scores and Thongprasom sign scoring. Firstly, the data from two studies allowing for VAS baseline versus 30-day follow-up analysis show statistically significant differences between them $(\mathrm{MD}=-3.52,95 \% \mathrm{CI}=-5.40,-1.64$, $p=0.0002$ ) (Fig. 3c). VAS scores baseline versus 60-day follow-up analysis was made considering two studies, and the results presented statistically significant differences between them $(\mathrm{MD}=-5.04,95 \% \mathrm{CI}=-5.86,-4.22$, $p<0.00001$ ) (Fig. 3d). Thongprasom sign scores were evaluated at baseline and 30-day follow-up from two studies, authors' judgements about each risk of bias item presented as percentages across all included studies

showing statistically significant differences between them $(\mathrm{MD}=-2.50,95 \% \mathrm{CI}=-2.92,-2.08, p<0.00001)$ (Fig. 3e). At 30-day follow-up after PBM, VAS and Thongprasom scores were significantly reduced; VAS score decreased by 3.52 points while Thongprasom score was reduced by 2.50 points. High levels of heterogeneity were observed only for VAS scores baseline versus 30-day followup $\left(I^{2}=70 \%\right)$; nevertheless, considering the nature of this score, meta-analysis was still carried out.

\section{Discussion}

Women with OLP were the most affected patients with DG, which agrees with literature as most autoimmune diseases are more prevalent in females than males $[1,49]$. Differences in prevalence and severity between genders result from complex and still poorly understood interactions involving hormonal and environmental factors in genetically susceptible individuals [50]. Estrogens are potent stimulators of autoimmunity and androgens seem to play a protective 
(a)

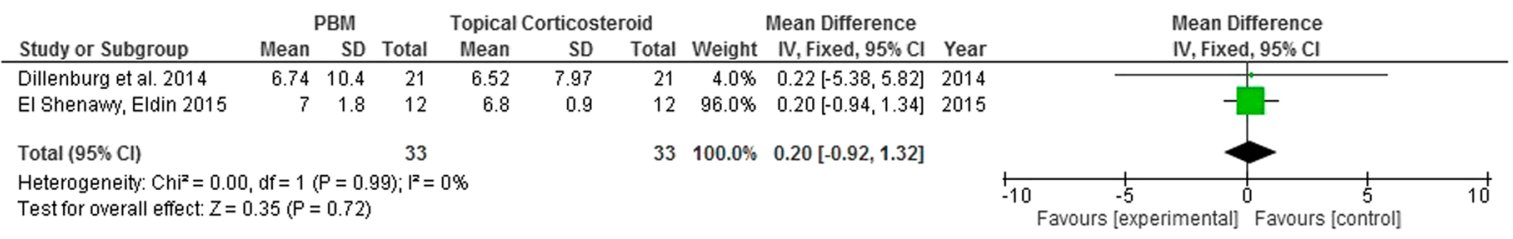

(b)

\begin{tabular}{|c|c|c|c|c|c|c|c|c|c|c|c|c|}
\hline \multirow[b]{2}{*}{ Study or Subgroup } & \multicolumn{3}{|c|}{ PBM } & \multicolumn{3}{|c|}{ Topical Corticosteroid } & \multicolumn{3}{|c|}{ Mean Difference } & \multirow{2}{*}{\multicolumn{3}{|c|}{$\begin{array}{l}\text { Mean Difference } \\
\text { IV, Random, } 95 \% \mathrm{Cl}\end{array}$}} \\
\hline & Mean & $S D$ & Total & Mean & SD & Total & Weight & IV, Random, $95 \% \mathrm{Cl}$ & Year & & & \\
\hline Dillenburg et al. 2014 & 1.21 & 1.42 & 21 & 2.86 & 2.56 & 21 & $51.0 \%$ & $-1.65[-2.90,-0.40]$ & 2014 & $-\square^{-1}$ & & \\
\hline El Shenawy, Eldin 2015 & 3.9 & 3 & 12 & 0.9 & 1 & 12 & $49.0 \%$ & $3.00[1.21,4.79]$ & 2015 & & & \\
\hline Total $(95 \% \mathrm{Cl})$ & & & 33 & & & 33 & $100.0 \%$ & $0.63[-3.93,5.19]$ & & & & \\
\hline $\begin{array}{l}\text { Heterogeneity: } \operatorname{Tau}^{2}=10 \text {. } \\
\text { Test for overall effect: } Z=\end{array}$ & $\begin{array}{l}9 ; \mathrm{Chi}^{2} \\
1.27(\mathrm{P}=\end{array}$ & $\begin{array}{l}=17.4 \\
=0.79)\end{array}$ & $2, d f=1$ & 0.4 & $2^{2}$ & & & & & $-10 \quad{ }^{-5}$ Favours [experimental] & Favo & thol] \\
\hline
\end{tabular}

(c)

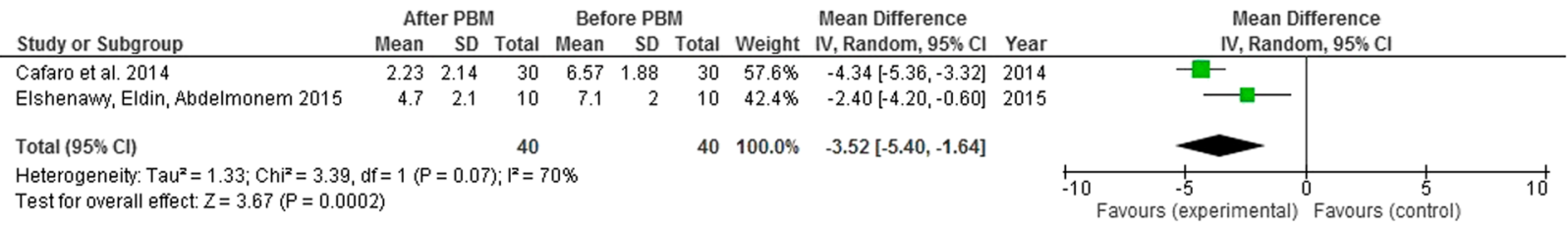

(d)

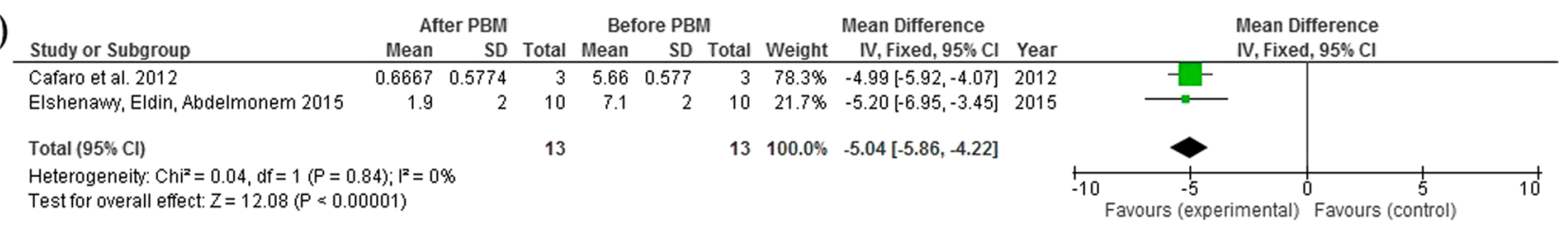

(e)

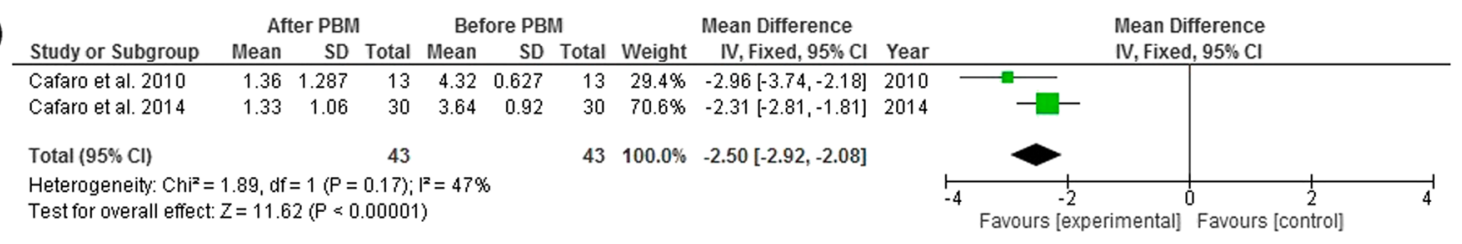

Fig. 3 Forest plots that graphically represent the meta-analysis of visual analog scale (VAS) and Thongprasom clinical scores. a VAS scores for PBM and topical CS groups at baseline. b VAS scores for PBM and topical CS groups at 60-day follow-up. c VAS scores at

role in the development of autoimmune diseases [51, 52]. However, the appearance of at least $50 \%$ of autoimmune disorders has been attributed to "unknown triggering factors" [53, 54]. Physical and psychological stress have been implicated in the development of these diseases, being one of the most commonly reported triggers for the progress of OLP, with greater predictability in females $[55,56]$. In addition, the COVID-19 pandemic is a current factor that has seriously affected mental health worldwide [57]. As people deal with quarantine, isolation, and travel restrictions, fear and chaos become evident and include fear of losing beloved ones, fear of losing sustenance, and phobia of contracting the SARS-CoV-2 infection, all of which impact mental health and quality of life of the subjects $[56,58,59]$. For patients baseline and at 30-day follow-up after PBM. d VAS scores at baseline and at 60-day follow-up after PBM. e Thongprasom clinical scores at baseline and at 30-day follow-up after PBM

with autoimmune disorders, COVID-19-related anxiety can lead to exacerbations of the disease [60].

Gingival lesions in autoimmune diseases usually present as diffuse erythematous areas, blisters, erosions, and ulcerations, located mainly in the attachment gingiva and/ or palatal mucosa, which may be surrounded by keratosis with tiny reticulations or with interspersed keratotic plaques $[3,16]$. However, due to the lack of data in the included articles, the most common gingival manifestation could not be established. Interesting data obtained in the current systematic review was that the gingival manifestation presented concomitantly with lesions in another oral location in $99.3 \%$ of the reported cases. Only one case presented as an isolated gingival lesion. Gingival tissue is recognized for its 
sensitivity to inflammation, fibrotic response, and propensity to drug-induced overgrowth $[61,62]$, which differentiates it from the lining mucosa in the oral cavity. In this sense, gingival lesions should be evaluated separately from other locations. Unfortunately, the revised papers did not perform such assessment, hindering the real response of the gingival tissue to treatment with PBM.

Topical CS remain the most widely used, most reliable, and effective method for the treatment of oral lesions of autoimmune origin, such as symptomatic OLP and MMP [30, 63]. Agents typically prescribed include betamethasone, clobetasol, dexamethasone, and triamcinolone acetonide [29]. Clobetasol propionate appears to be one of the most effective topical steroids as on an adhesive basis it led to complete remission in 56-75\% of patients [30]. The symptomatic treatment with CS can eradicate pain and ulcers, allowing patients to recover their capacity for basic activities of daily life (e.g., eating, drinking, toothbrushing). There is often an improvement in the clinical aspect of the affected areas and the treatment can be considered successful when a painful erosive lesion is transformed into a painless atrophic change [64]. Nonetheless, some patients are refractory to topical corticosteroids [30]. The lack of adherence of the topical drug formulation to the affected sites for a longer duration has been considered as a factor in reducing the efficacy of this treatment [20]. In addition, the use of CS may also result in the development of secondary candidiasis, and thus frequently requires concomitant use of antifungal agents [65]. The disadvantages of CS point to the need for seeking new treatment alternatives. Thereby, PBM appears as a therapeutic option for these injuries.

PBM is a treatment that uses a continuous laser or lightemitting diode (LED) with a wavelength of 600 to $1000 \mathrm{~nm}$ applied for the purpose of analgesia, stimulation of tissue repair, and/or reduction of inflammation, showing advantages over current OLP therapies such as noninvasiveness and the absence of side effects $[42,66]$. The qualitative evaluation showed that all included studies reported the effect of PBM on pain alleviation and clinical enhancement of the oral lesions. Moreover, the meta-analysis revealed no statistically significant differences between PBM and topical CS groups in reducing pain. Therefore, considering that topical CS are the first-line therapy for many autoimmune diseases, such as OLP [67], PBM has proved to be as effective as topical CS, and can be considered an option for patients with restrictions on the use of these medications. Furthermore, PBM does not lead to side effects inherent to the medication, such as oral candidiasis.

The low number of included RCT with the same evaluation criteria and few evaluated patients in each included study represents a limitation. Additionally, one study was responsible for $96 \%$ of the weight in the analysis, which could be improved if there were a greater number of included studies. Baseline analysis showed an absence of sample heterogeneity, demonstrating that the sample used in the studies had similar characteristics between the evaluated groups. However, at 60-day follow-up analysis, there was great heterogeneity in the sample $\left(I^{2}=94 \%\right)$, with very divergent results, which contributed to the absence of significant differences between the evaluated studies; it is noteworthy that the weight distribution in the present analysis was more uniform compared to the baseline analysis. Again, the lack of randomized controlled trials with the same assessment tool leads to an analysis with little strong evidence.

Concerning the analyses of laser outcome (effect over time) using pain and Thongprasom clinical scores, results are very favorable to the use of PBM in autoimmune gingival lesions, even with a heterogeneous sample in the VAS evaluation (baseline and 30-day comparison; $I^{2}=70 \%$ ). It was also observed that the improvement in pain extends up to 60 days of follow-up, showing a homogeneous sample $\left(I^{2}=0 \%\right)$. These results present some limitations; first, in the 60-day analysis, there was irregular distribution of weight, with one study accounting for $78.3 \%$ of the weight in the analysis; second, both VAS analyses were performed with only 2 studies, with no other papers fulfilling the necessary criteria. Concerning Thongprasom analysis, more homogeneous sample is noted $\left(I^{2}=47 \%\right)$; however, the irregular distribution of weight remains as a limitation, with one study representing $70.6 \%$ of weight in the analysis.

A variety of scoring systems have been proposed to evaluate disease severity and monitor the response to such treatments, testing the effectiveness of these drugs within and among patients [68]. VAS and Thongprasom sign scores are the most used methods in the analysis of pain and clinical evaluation of OLP, respectively [68, 69]. VAS was developed to obtain pain measurements with more variability using a continuous single-line trace [70]. In addition to VAS, the NRS system is also considered to be highly feasible for clinical research and practice, providing very little burden to professionals and patients [69]. Despite the validated tools for pain assessment, measuring the subjective experience of pain is a continuing challenge in the medicine [71]. To analyze clinical improvement, Thongprasom's score is typically preferred by investigators because of its ease of application and it does not require any sophisticated calculations [68].

The laser parameters used in the included studies showed great variation. Data including source, wavelength, fluence, power output, power density, time of irradiation, number of sessions, and spot size were collected from the selected studies. The mostly used laser source was a diode laser, which consists of a system of many semiconductors designated as conductor bands or valence bands, between which the flow of electric current causes the excitation of electrons and the creation of a laser wave with wavelengths ranging from 445 to $980 \mathrm{~nm}$ [72]. Wavelength affects tissue penetration; 
shorter wavelengths (600 to $700 \mathrm{~nm}$ ) are considered best to treat superficial lesions, whereas longer wavelengths (780 to $950 \mathrm{~nm}$ ) are preferred to treat deeper injuries [73]. Our results indicate a preference for longer wavelengths, considering that DG is an immune-mediated condition and not a superficial damage that is heavily influenced by external factors or contactants. In all studies, laser was used with wavelengths ranging from 308 to $10,600 \mathrm{~nm}$. Considering that photons emitted by a light source are absorbed by cytochrome $\mathrm{C}$ oxidase mainly located in mitochondria, cells with greater amount of this organelle respond better to PBM; besides, tissues with more mitochondria tend to be located deeper in the body [73], supporting the use of longer wavelengths.

Irradiation time is also important in establishing the optimal light delivery protocol; for arthritides (inflammatory chronic rheumatic diseases), a higher time of exposure produces positive effects on reduction of joint swelling and serum prostaglandin E2 [74]. Interestingly, the effect in arthritides is independent of the fluence or irradiance [74]. Nevertheless, the current systematic review showed that two studies with no favorable results for PBM in DG presented higher irradiation times (120 [37] and 480 [44] s per point), indicating that laser protocols need to be individualized for each pathology.

Another important parameter is the spot size; the application of a larger surface optical spot size is associated with optimal clinical outcome for deeper targets [75]. On the other hand, smaller spot size presents better results associated to multiple applications and higher overall dose [75]. In the present review, the spot size ranged between 0.03 and $1 \mathrm{~cm}^{2}$; unfortunately, $58.8 \%$ of the included studies did not report this laser parameter, making it difficult to state whether spot size is associated or not with improved gingival lesions. Concerning power density (irradiance), it should be suitable; upper intensity can generate unnecessary heat in the target tissue or lesion, and lower intensity can be deficient to reach the clinical improvement [73]. Only four studies $[9,30,42,43]$ reported the irradiance, the majority comprised higher values $\left(1000\right.$ or $\left.1500 \mathrm{~mW} / \mathrm{cm}^{2}\right)$, and showed favorable response of PBM in autoimmune gingival lesions.

The dose or fluence is a laser parameter in function of the power output, application time, and optical footprint within the tissues; therefore, some applied energy is reflected, whereas other fraction of energy is scattered around the target tissue, and finally the remaining is absorbed by the tissue, producing the positive effects of PBM [75]. Currently, there is no single established protocol of dose or fluence that will always result in a beneficial PBM effect [73]. In fact, our results showed great variability in this parameter, ranging from 0.1 up to $133.3 \mathrm{~J} / \mathrm{cm}^{2}$, and presenting good response of PBM in gingival lesions. Only two studies [37, 44] reported no positive effects of PBM, but they did not inform the utilized fluence, which made further assessment of this parameter not possible.

Some limitations were observed in the present study. The lack of well-conducted RCTs was a factor that hampered better assessing of PBM effectiveness; most of the studies systematically included in this review were case reports and case series, making a stronger meta-analysis unfeasible. Another limitation refers to the absence of clinical information about gingival injuries in several studies, as well as the lack of individual analysis, separating gingival lesions from others, which would allow a more reliable assessment of the effects of PBM on gingival tissue. Our results highlight the need for conducting more RCT-type studies that investigate the use of PBM in autoimmune gingival lesions, besides emphasizing the importance that the studies present their data in more detail about the response to treatment in each specific location, given the different responses presented by lesions in different intraoral sites.

In conclusion, PBM has become an important tool in the management of autoimmune gingival lesions and has shown significant pain reduction and improvement of clinical scores of the intraoral lesions after therapy, without showing significant differences when compared to topical CS. Up to now, there is limited strong evidence to assess the efficacy of PBM in autoimmune gingival lesions.

Author contribution MMC, MLC, and SCP contributed to study conception and design and data collection. MARH, RMSC, MMC, MLC, and SCP contributed to statistical analysis and data interpretation. NVRJ and FFS contributed to data interpretation. All the authors contributed to the manuscript draft and to critically revising the manuscript.

Funding The present study is financially supported by the Conselho Nacional de Desenvolvimento Científico e Tecnológico (CNPq), Grant/ Award Number: MCTIC Universal no 408884/2018-5; Coordenação de Aperfeiçoamento de Pessoal de Nível Superior (CAPES), Grant/Award Number: Finance Code 001, and Fundação de Amparo à Pesquisa do Estado de Minas Gerais (FAPEMIG).

\section{Declarations}

Conflict of interest The authors declare no competing interests.

\section{References}

1. Ortona E, Pierdominici M, Maselli A, Veroni C, Aloisi F, Shoenfeld Y (2016) Sex-based differences in autoimmune diseases. Ann Ist Super Sanita 52:205-212. https://doi.org/10.4415/ANN_16_ 02_12

2. Wang L, Wang FS, Gershwin ME (2015) Human autoimmune diseases: a comprehensive update. J Intern Med 278:369-395. https://doi.org/10.1111/joim.12395

3. Arduino PG, Romano F, Sasia D, Broccoletti R, Ricceri F, Barbui AM, Brossa S, Cipriani R, Cricenti L, Cabras M, Aimetti M 
(2017) Subgingival microbiota in white patients with desquamative gingivitis: a cross-sectional study. J Periodontol 88:643-650. https://doi.org/10.1902/jop.2017.160745

4. Mustafa MB, Porter SR, Smoller BR, Sitaru C (2015) Oral mucosal manifestations of autoimmune skin diseases. Autoimmun Rev 14:930-951. https://doi.org/10.1016/j.autrev.2015.06. 005

5. Paiva SN, Braga CC, Almeida-Coburn KL, Bautz WG, de Barros LAP, da Gama-de-Souza LN (2016) Oral lichen planus: clinical profile and determination of oral epithelial dysplasia. Int J Odontostomat 10:99-106

6. Carrozzo M, Porter S, Mercadante V (2000) Fedele S (2019) Oral lichen planus: a disease or a spectrum of tissue reactions? Types, causes, diagnostic algorhythms, prognosis, management strategies. Periodontol 80:105-125. https://doi.org/10.1111/prd.12260

7. Zakrzewska JM (2001) Re: Mollaoglu N. Oral lichen planus: a review. Br J Oral Maxillofac Surg 2000; 38: 370-377. Br J Oral Maxillofac Surg 39:407 https://doi.org/10.1054/bjom.2000.0555

8. Shivhare P, Gupta A, Yadav M, Konidena A, Shankarnarayan L (2016) Evaluation of different diagnostic criteria of diseases manifesting the oral cavity - a review. Part-1. J Oral Biol Craniofac Res 6:135-141. https://doi.org/10.1016/j.jobcr.2015.12.012

9. Cafaro A, Broccoletti R, Arduino PG (2012) Low-level laser therapy for oral mucous membrane pemphigoid. Lasers Med Sci 27:1247-1250. https://doi.org/10.1007/s10103-012-1137-9

10. Chan LS (2001) Mucous membrane pemphigoid. Clin Dermatol 19:703-711. https://doi.org/10.1016/s0738-081x(00)00196-6

11. Lo Russo L, Gallo C, Pellegrino G, Lo Muzio L, Pizzo G, Campisi G, Di Fede O (2014) Periodontal clinical and microbiological data in desquamative gingivitis patients. Clin Oral Investig 18:917925. https://doi.org/10.1007/s00784-013-1038-8

12. Arduino PG, Farci V, D'Aiuto F, Carcieri P, Carbone M, Tanteri C, Gardino N, Gandolfo S, Carrozzo M, Broccoletti R (2011) Periodontal status in oral mucous membrane pemphigoid: initial results of a case-control study. Oral Dis 17:90-94. https://doi.org/ 10.1111/j.1601-0825.2010.01709.x

13. Porro AM, Seque CA, Ferreira MCC, Enokihara M (2019) Pemphigus vulgaris. An Bras Dermatol 94:264-278. https://doi.org/ 10.1590/abd1806-4841.20199011

14. Dal Prá KJ, de Assis TS, Franco JB, Matias DT, Carrillo CM, de Melo Peres MPS, Ribas PF (2020) Oral management of pemphigus vulgaris in the intensive care unit. Spec Care Dentist 40:280284. https://doi.org/10.1111/scd.12454

15. Zand N, Mansouri P, Fateh M, Ataie-Fashtami L, Khiabanloo SR, Safar F, Chalangari R, Martits K, Shirkavand A (2017) Relieving pain in oral lesions of pemphigus vulgaris using the non-ablative, non-thermal, $\mathrm{CO} 2$ laser therapy (NTCLT): preliminary results of a novel approach. J Lasers Med Sci 8:8-12. https://doi.org/10. 15171/jlms.2017.02

16. Lo Russo L, Fedele S, Guiglia R, Ciavarella D, Lo Muzio L, Gallo P, Di Liberto C, Campisi G (2008) Diagnostic pathways and clinical significance of desquamative gingivitis. J Periodontol 79:4-24. https://doi.org/10.1902/jop.2008.070231

17. Garcia-Pola MJ, Rodriguez-Lopez S, Fernanz-Vigil A, Bagan L, Garcia-Martin JM (2019) Oral hygiene instructions and professional control as part of the treatment of desquamative gingivitis. Systematic review. Med Oral Patol Oral Cir Bucal 24:e136-e144. https://doi.org/10.4317/medoral.22782

18. Maderal AD, LeeSalisbury P 3rd, Jorizzo JL (2018) Desquamative gingivitis: clinical findings and diseases. J Am Acad Dermatol 78:839-848. https://doi.org/10.1016/j.jaad.2017.05.056

19. Scully C, Carrozzo M, Gandolfo S, Puiatti P, Monteil R (1999) Update on mucous membrane pemphigoid: a heterogeneous immune-mediated subepithelial blistering entity. Oral Surg Oral Med Oral Pathol Oral Radiol Endod 88:56-68. https://doi.org/10. 1016/s1079-2104(99)70194-0
20. Nisengard RJ, Rogers RS 3rd (1987) The treatment of desquamative gingival lesions. J Periodontol 58:167-172. https://doi.org/ 10.1902/jop.1987.58.3.167

21. Nisengard RJ, Neiders M (1981) Desquamative lesions of the gingiva. J Periodontol 52:500-510. https://doi.org/10.1902/jop.1981. 52.9.500

22. Markopoulos AK, Antoniades D, Papanayotou P, Trigonidis G (1996) Desquamative gingivitis: a clinical, histopathologic, and immunologic study. Quintessence Int 27:763-767

23. Rogers RS 3rd, Sheridan PJ, Nightingale SH (1982) Desquamative gingivitis: clinical, histopathologic, immunopathologic, and therapeutic observations. J Am Acad Dermatol 7:729-735. https:// doi.org/10.1016/s0190-9622(82)70153-7

24. Yih WY, Maier T, Kratochvil FJ, Zieper MB (1998) Analysis of desquamative gingivitis using direct immunofluorescence in conjunction with histology. J Periodontol 69:678-685. https://doi. org/10.1902/jop.1998.69.6.678

25. Yih WY, Richardson L, Kratochvil FJ, Avera SP, Zieper MB (2000) Expression of estrogen receptors in desquamative gingivitis. J Periodontol 71:482-487. https://doi.org/10.1902/jop.2000. 71.3 .482

26 Karagoz G, Bektas-Kayhan K, Unur M (2016) Desquamative gingivitis: a review. J Istanb Univ Fac Dent 50:54. https://doi.org/10. 17096/jiufd.57228

27. Beck JD, Philips K, Moss K, Divaris K, Morelli T, Offenbacher S (2020) Adv precis oral health Periodontol 2000(82):268-285. https://doi.org/10.1111/prd.12314

28. Sobanko JF, Alster TS (2008) Efficacy of low-level laser therapy for chronic cutaneous ulceration in humans: a review and discussion. Dermatol Surg 34:991-1000. https://doi.org/10.1111/j. 1524-4725.2008.34197.x

29. Jajarm HH, Asadi R, Bardideh E, Shafaee H, Khazaei Y, Emadzadeh M (2018) The effects of photodynamic and low-level laser therapy for treatment of oral lichen planus-a systematic review and meta-analysis. Photodiagnosis Photodyn Ther 23:254-260. https://doi.org/10.1016/j.pdpdt.2018.07.001

30. Cafaro A, Arduino PG, Massolini G, Romagnoli E, Broccoletti $R$ (2014) Clinical evaluation of the efficiency of low-level laser therapy for oral lichen planus: a prospective case series. Lasers Med Sci 29:185-190. https://doi.org/10.1007/s10103-013-1313-6

31. Murad MH, Sultan S, Haffar S, Bazerbachi F (2018) Methodological quality and synthesis of case series and case reports. BMJ Evid Based Med 23:60-63. https://doi.org/10.1136/ bmjebm-2017-110853

32. Higgins JPT, Altman DG, Sterne JAC, Chapter 8: Assessing risk of bias in included studies, in Cochrane handbook for systematic reviews of interventions version 5.2.0, J.P.T. Higgins, et al., Editors. 2017, Cochrane.

33. Kim SY, Park JE, Lee YJ, Seo HJ, Sheen SS, Hahn S, Jang BH, Son HJ (2013) Testing a tool for assessing the risk of bias for nonrandomized studies showed moderate reliability and promising validity. J Clin Epidemiol 66:408-414. https://doi.org/10.1016/j. jclinepi.2012.09.016

34. Thongprasom K, Luangjarmekorn L, Sererat T, Taweesap W (1992) Relative efficacy of fiuocinolone acetonide compared with triamcinolone acetonide in treatment of oral lichen planus. J Oral Pathol Med 21:456-458

35. Agha-Hosseini F, Moslemi E, Mirzaii-Dizgah I (2012) Comparative evaluation of low-level laser and $\mathrm{CO} 2$ laser in treatment of patients with oral lichen planus. Int J Oral Maxillofac Surg 41:1265-1269. https://doi.org/10.1016/j.ijom.2012.06.001

36. Elshenawy HM, Eldin AM, Abdelmonem MA (2015) Clinical assessment of the efficiency of low level laser therapy in the treatment of oral lichen planus. Open Access Maced J Med Sci 3:717-721. https://doi.org/10.3889/oamjms.2015.112 
37. El Shenawy HM, Eldin AM (2015) A comparative evaluation of low-level laser and topical steroid therapies for the treatment of erosive-atrophic lichen planus. Open Access Maced J Med Sci 3:462-466. https://doi.org/10.3889/oamjms.2015.072

38. Yilmaz HG, Kusakci-Seker B, Bayindir H, Tözüm TF (2010) Low-level laser therapy in the treatment of mucous membrane pemphigoid: a promising procedure. J Periodontol 81:1226-1230. https://doi.org/10.1902/jop.2010.100095

39. Zand N, Mansouri P, RezaeeKhiabanloo S, Fateh M, AtaieFashtami L, SafaeeNaraghi Z, Shirkavand A (2020) The immediate pain-relieving effects of non-thermal $\mathrm{CO} 2$ laser therapy on genital ulcers of Behcet's disease: a case report. Journal of Lasers in Medical Sciences 11:108-111. https://doi.org/10.15171/jlms. 2020.18

40. Mutafchieva MZ, Draganova-Filipova MN, Zagorchev PI, Tomov GT (2018) Effects of low level laser therapy on erosive-atrophic oral lichen planus. Folia Med (Plovdiv) 60:417-424. https://doi. org/10.2478/folmed-2018-0008

41. Cafaro A, Albanese G, Arduino PG, Mario C, Massolini G, Mozzati M, Broccoletti R (2010) Effect of low-level laser irradiation on unresponsive oral lichen planus: early preliminary results in 13 patients. Photomed Laser Surg 28(Suppl 2):S99-103. https:// doi.org/10.1089/pho.2009.2655

42. Dillenburg CS, Martins MAT, Munerato MC, Marques MM, Carrard VC, Filho MS, Castilho RM, Martins MD (2014) Efficacy of laser phototherapy in comparison to topical clobetasol for the treatment of oral lichen planus: a randomized controlled trial. J Biomed Opt 19:068002. https://doi.org/10.1117/1.JBO.19.6. 068002

43 Derikvand N, Ghasemi SS, Moharami M, Shafiei E, Chiniforush N (2017) Management of oral lichen planus by $980 \mathrm{~nm}$ diode laser. J Lasers Med Sci 8:150-154. https://doi.org/10.15171/jlms.2017.27

44. Othman NA, Shaker OG, Elshenawy HM, Abd-Elmoniem W, Eldin AM, Fakhr MY (2016) The effect of diode laser and topical steroid on serum level of TNF-alpha in oral lichen planus patients. J Clin Exp Dent 8:e566-e570. https://doi.org/10.4317/jced.52665

45. Liu WB, Sun LW, Yang H, Wang YF (2017) Treatment of oral lichen planus using 308-nm excimer laser. Dermatol Ther 30:1-3. https://doi.org/10.1111/dth.12510

46. Oliveira PC, Reis JA, Lacerda JA, Silveira NT, Santos JM, Vitale MC, Pinheiro ALB (2009) Laser light may improve the symptoms of oral lesions of cicatricial pemphigoid: a case report. Photomed Laser Surg 27:825-828. https://doi.org/10.1089/pho.2008.2352

47. Fornaini C (2012) LLLT in the symptomatic treatment of oral lichen planus. Laser Ther 21:51-53. https://doi.org/10.5978/islsm. 12-CR-03

48. Trehan M, Taylor CR (2004) Low-dose excimer 308-nm laser for the treatment of oral lichen planus. Arch Dermatol 140:415-420. https://doi.org/10.1001/archderm.140.4.415

49. Ngo ST, Steyn FJ, McCombe PA (2014) Gender differences in autoimmune disease. Front Neuroendocrinol 35:347-369. https:// doi.org/10.1016/j.yfrne.2014.04.004

50. Moulton VR (2018) Sex hormones in acquired immunity and autoimmune disease. Front Immunol 9:2279. https://doi.org/10.3389/ fimmu.2018.02279

51. Zandman-Goddard G, Peeva E, Shoenfeld Y (2007) Gender and autoimmunity. Autoimmun Rev 6:366-372. https://doi.org/10. 1016/j.autrev.2006.10.001

52. Quintero OL, Amador-Patarroyo MJ, Montoya-Ortiz G, RojasVillarraga A, Anaya JM (2012) Autoimmune disease and gender: plausible mechanisms for the female predominance of autoimmunity. J Autoimmun 38:J109-119. https://doi.org/10.1016/j.jaut. 2011.10.003

53. Herrmann M, Schölmerich J, Straub RH (2000) Stress and rheumatic diseases. Rheum Dis Clin North Am 26:737-763, viii. https://doi.org/10.1016/s0889-857x(05)70167-8
54. Stojanovich L, Marisavljevich D (2008) Stress as a trigger of autoimmune disease. Autoimmun Rev 7:209-213. https://doi.org/10. 1016/j.autrev.2007.11.007

55. Chen HX, Blasiak R, Kim E, Padilla R, Culton DA (2017) Triggers of oral lichen planus flares and the potential role of trigger avoidance in disease management. Oral Surg Oral Med Oral Pathol Oral Radiol 124:248-252. https://doi.org/10.1016/j.oooo. 2017.05.508

56. Moccia L, Janiri D, Pepe M, Dattoli L, Molinaro M, De Martin V, Chieffo D, Janiri L, Fiorillo A, Sani G, Di Nicola M (2020) Affective temperament, attachment style, and the psychological impact of the COVID-19 outbreak: an early report on the Italian general population. Brain Behav Immun 87:75-79. https://doi.org/ 10.1016/j.bbi.2020.04.048

57. Vissink CE, van Hell HH, Galenkamp N, van Rossum IW (2021) The effects of the COVID-19 outbreak and measures in patients with a pre-existing psychiatric diagnosis: a cross-sectional study. J Affect Disord Rep 4:100102. https://doi.org/10.1016/j.jadr.2021. 100102

58. Routray S, Mishra P (2020) A probable surge in oral lichen planus cases under the aura of coronavirus in females in India. Oral Oncol 109:104714. https://doi.org/10.1016/j.oraloncology.2020. 104714

59. Capuano R, Altieri M, Bisecco A, d'Ambrosio A, Docimo R, Buonanno D, Matrone F, Giuliano F, Tedeschi G, Santangelo G, Gallo A (2021) Psychological consequences of COVID-19 pandemic in Italian MS patients: signs of resilience? J Neurol 268:743-750. https://doi.org/10.1007/s00415-020-10099-9

60. Stojanov A, Malobabic M, Milosevic V, Stojanov J, Vojinovic S, Stanojevic G, Stevic M (2020) Psychological status of patients with relapsing-remitting multiple sclerosis during coronavirus disease-2019 outbreak. Mult Scler Relat Disord 45:102407. https:// doi.org/10.1016/j.msard.2020.102407

61. Garlet GP (2010) Destructive and protective roles of cytokines in periodontitis: a re-appraisal from host defense and tissue destruction viewpoints. J Dent Res 89:1349-1363. https://doi.org/10. $1177 / 0022034510376402$

62. Nakasone N, Kubota T, Hoshino C, Nohno K, Itagaki M, Shimizu $\mathrm{T}$, Yoshie H (2009) Differential gene and protein expression of tissue inhibitors of metalloproteinases (TIMP)-3 and TIMP-4 in gingival tissues from drug induced gingival overgrowth. Arch Oral Biol 54:634-641. https://doi.org/10.1016/j.archoralbio.2009.04.002

63. Xu HH, Werth VP, Parisi E, Sollecito TP (2013) Mucous membrane pemphigoid. Dent Clin North Am 57:611-630. https://doi. org/10.1016/j.cden.2013.07.003

64. Gonzalez-Moles MA, Bravo M, Gonzalez-Ruiz L, Ramos P, Gil-Montoya JA (2018) Outcomes of oral lichen planus and oral lichenoid lesions treated with topical corticosteroid. Oral Dis 24:573-579. https://doi.org/10.1111/odi.12803

65. Mollaoglu N (2000) Oral lichen planus: a review. Br J Oral Maxillofac Surg 38:370-377. https://doi.org/10.1054/bjom.2000.0335

66. Chung H, Dai T, Sharma SK, Huang YY, Carroll JD, Hamblin MR (2012) The nuts and bolts of low-level laser (light) therapy. Ann Biomed Eng 40:516-533. https://doi.org/10.1007/ s10439-011-0454-7

67. Farhi D, Dupin N (2010) Pathophysiology, etiologic factors, and clinical management of oral lichen planus, part I: Facts and controversies. Clin Dermatol 28:100-108. https://doi.org/10.1016/j. clindermatol.2009.03.004

68. Elsabagh HH, Gaweesh YY, Ghonima JK, Gebril M (2021) A novel comprehensive scoring system for oral lichen planus: a validity, diagnostic accuracy, and clinical sensitivity study. Oral Surg Oral Med Oral Pathol Oral Radiol 131:304-311. https://doi. org/10.1016/j.oooo.2020.12.016

69. Chiarotto A, Maxwell LJ, Ostelo RW, Boers M, Tugwell P, Terwee CB (2019) Measurement properties of visual analogue scale, 
numeric rating scale, and pain severity subscale of the brief pain inventory in patients with low back pain: a systematic review. J Pain 20:245-263. https://doi.org/10.1016/j.jpain.2018.07.009

70. Sung YT, Wu JS (2018) The Visual Analogue Scale for rating, ranking and paired-comparison (VAS-RRP): a new technique for psychological measurement. Behav Res Methods 50:1694-1715. https://doi.org/10.3758/s13428-018-1041-8

71. Heller GZ, Manuguerra M, Chow R (2016) How to analyze the Visual Analogue Scale: myths, truths and clinical relevance. Scand J Pain 13:67-75. https://doi.org/10.1016/j.sjpain.2016.06. 012

72. Dompe C, Moncrieff L, Matys J, Grzech-Lesniak K, Kocherova I, Bryja A, Bruska M, Dominiak M, Mozdziak P, Skiba THI, Shibli JA, Angelova Volponi A, Kempisty B, Dyszkiewicz-Konwinska M (2020) Photobiomodulation-underlying mechanism and clinical applications. J Clin Med 9:1724. https://doi.org/10.3390/jcm90 61724
73. Zein R, Selting W, Hamblin MR (2018) Review of light parameters and photobiomodulation efficacy: dive into complexity. J Biomed Opt 23:1-17. https://doi.org/10.1117/1.JBO.23.12. 120901

74. Castano AP, Dai T, Yaroslavsky I, Cohen R, Apruzzese WA, Smotrich MH, Hamblin MR (2007) Low-level laser therapy for zymosan-induced arthritis in rats: importance of illumination time. Lasers Surg Med 39:543-550. https://doi.org/10.1002/1sm. 20516

75. Cronshaw M, Parker S, Anagnostaki E, Mylona V, Lynch E, Grootveld M (2020) Photobiomodulation dose parameters in dentistry: a systematic review and meta-analysis. Dent J (Basel) 8:114. https://doi.org/10.3390/dj8040114

Publisher's note Springer Nature remains neutral with regard to jurisdictional claims in published maps and institutional affiliations. 